\title{
Microfoundations of institutions: A matter of structure vs. agency or level of analysis?
}

\author{
Derek J Harmon \\ Ross School of Business \\ University of Michigan \\ Patrick Haack \\ HEC Lausanne \\ University of Lausanne \\ Thomas J Roulet \\ Judge Business School \\ University of Cambridge
}

Dialogue paper in response to:

Cardinale, I. 2018. Beyond constraining and enabling: Toward new microfoundations for institutional theory. Academy of Management Review, 43, 132-155.

Forthcoming at the Academy of Management Review

https://doi.org/10.5465/amr.2018.0080

(C) 2018. This manuscript version is made available under the CC-BY-NC-ND 4.0 license http://creativecommons.org/licenses/by-nc-nd/4.0/ 


\section{Microfoundations of institutions:}

\section{A matter of structure vs. agency or level of analysis?}

In his recent paper, Cardinale (2018) seeks to advance a new microfoundations of institutions by reformulating two assumptions underlying the structure vs. agency debatethat structure constrains and enables action and that agency is mostly associated with reflexivity—which he argues have been hindering the field's ability to make substantive theoretical progress. While an intriguing proposition, we argue that equating the microfoundations of institutions with the structure vs. agency dichotomy produces two problems that limit our advancement of this stream of work. First, it leads to the mistaken assumption that the best way to advance our theorizing is to provide another solution to the paradox of embedded agency. Second, it also leads to the mistaken assumption that, by the "micro" in microfoundations, we are rigidly focusing on the role of individuals in institutional processes. We outline the strengths of Cardinale's argument and then argue that a focus on levels of analysis, which is backgrounded in Cardinale's theorizing, would serve as a more promising platform upon which to advance our understanding of the microfoundations of institutions.

\section{Starting with structure vs. agency}

Cardinale's two major reformulations to the structure-agency debate are to claim that structure not only constrains and enables action but also "orients" action towards certain possibilities, and that agency is not only reflective but can also be pre-reflective in nature. To make these claims, Cardinale draws on a practice perspective lens (Smets, Aristidou, \& Whittington, 2017) so that he can conceptualize social structure as social positions and habitus. Conceptualizing social structure in this manner, instead of as more macro constructs (e.g., logics, fields, complexity, etc.), is an important theoretical move for Cardinale. In particular, it allows him to explain that social structure does not influence individual behavior in an automatic or mindless fashion, which more macro structural concepts are often accused 
of doing, but rather, in an orienting and pre-reflective fashion that is guided by our historical positioning and habitus. We find this point insightful insofar as it provides one reasonable solution to the paradox of embedded agency (Battilana \& D'Aunno, 2009; Garud, Hardy, \& Maguire, 2007). By defining social structure as social positions or habitus, Cardinale is able to critique the oversimplified parallel sometimes made between structure only producing mindless individual behavior, and individuals shaping structure only in a deliberate fashion. Yet, does it move us towards a new microfoundations of institutional theory?

\section{What are microfoundations?}

From our point of view, a microfoundational approach to institutions seeks to explain the recursive relationships between macro-level phenomena through some lower level of analysis. This is often referred to as the "bathtub model" of Coleman (1986), which outlines the basic principles of methodological individualist approach to social action (Felin, Foss, \& Ployhart, 2015). According to the more stringent forms of this approach, all macro phenomena are really just aggregated forms of individual-level behavior. However, our view is less stringent and consistent with more sympathetic forms of methodological individualism (Udehn, 2002) that acknowledge two important complexities overlooked by the traditional "bathtub model." The first is that there are more than two levels of analysis beyond the social system and the individual (e.g., organization, group, etc.). The second, by extension of the first, is that the lower levels of analysis do not require us to mean individuals per se. In our view, it follows from this that the basis for a microfoundations of institutions should start, first and foremost, with a focus on levels of analysis.

Note, however, that this statement is not antithetical to the structure-agency debate. In fact, the traditional mapping of macro-structure and micro-agency, which has pervaded the institutional discussions on microfoundations for some time now (Emirbayer \& Mische, 1998), often directly links the two traditional levels of analysis with the structure-agency dichotomy. However, to take this mapping and conclude that examining how macro levels of 
analysis shape micro levels of analysis (and vice versa) is identical to examining how structure shapes agency (and vice versa) overlooks the fact that this traditional one-to-one mapping often does not hold. For instance, there are more micro-level instantiations of social structure (e.g., social positions, habitus, routines, etc.) that are clearly embedded within social structures at a higher level of analysis. Similarly, there are also macro-level instantiations of agency (e.g., collective action, social movements, crowdsourcing, etc.) that some contend are not simply the aggregation of individual-level behavior (Jepperson \& Meyer, 2011). As a result, actors can "pull down" structural elements for their actions, and local practices can "build up" into structure (Powell \& Rerup, 2017). The notion of macro and micro is thus distinct from structure and agency.

Yet while this traditional mapping of macro-structure and micro-agency does not always hold, we want to be clear that both distinctions seem to always be simultaneously present in our institutional analyses and both require serious consideration. However, we suggest that the key question is which to prioritize in our theorizing. Since they do not perfectly map onto one another and, therefore, highlight important yet nevertheless different considerations, we contend that prioritizing one over the other may lead to very different assumptions of what matters when developing the microfoundations of institutions. For instance, to foreground structure vs. agency means that we implicitly prioritize the puzzle of embedded agency, which, by extension, leads us to conceptualize the "micro" in microfoundations as individuals. What would foregrounding levels of analysis instead mean?

\section{Starting with levels of analysis}

To foreground levels of analysis shifts the focus away from the problem of embedded agency, and back towards the core aim of microfoundational research — that is, explaining the causal and recursive relationships between macro-level phenomena through phenomena at lower levels of analysis. A number of institutional scholars already contribute to this line of reasoning, implicitly prioritizing levels of analysis over the structure-agency dichotomy. For 
example, some have focused on how macro-level meanings, like institutional logics, make their way into micro-level thinking (Glaser, Fast, Harmon, \& Green Jr, 2016) and decisionmaking (McPherson \& Sauder, 2013). Others have looked at how micro-level behaviors and interactions can build up to change or further maintain meso- and macro-level meanings (Cornelissen, Durand, Fiss, Lammers, \& Vaara, 2015; Zucker, 1977). By focusing on the complexities and interrelationships across multiple levels of analysis, we believe this provides a more direct explanation to how macro-level institutional meanings persist or change or time.

Foregrounding levels of analysis also removes the requirement that by the "micro" in microfoundations, we are referring only to individuals. When considering the nested nature of institutions (Friedland \& Alford, 1991), everything is micro to something and macro to something else. An individual's values are micro to routines, even more micro to logics, but macro to emerging research on the neuroscience of decision-making (Laureiro-Martínez, Brusoni, Canessa, \& Zollo, 2015). Removing our presumption that individuals are the only conceptualization of micro, therefore, frees up our theorizing and enables us to consider the deeper complexities of the multi-layered nature of institutions. For instance, not every macroinstitutional outcome requires or, for that matter, has an individual-level explanation. Indeed, some macro-institutional outcomes may be explained by group-level behavior, making it not just unnecessary but theoretically inappropriate to treat the micro-level of analysis in such a study as another other than the group (Jepperson \& Meyer, 2011) or the organization as an actor sui generis (King, Felin, \& Whetten, 2010).

From this point of view, while Cardinale does not directly acknowledge the importance of levels of analysis, what we find intriguing about his study is that he nevertheless introduces social positioning and habitus as crucial "meso" levels of analysis that mediate more macro structures and micro-level behavior. In fact, microfoundational research often skips over these intermediate levels of analysis, conceptualizing social structure only as logics or fields (Thornton, Ocasio, \& Lounsbury, 2012). We think that bringing social 
structure down to a meso-level is an insightful and potentially useful observation in that it suggests that social positions and habitus might function as a refracting, intermediate level between more macro meanings and micro behaviors. However, by not further developing the implications of this insight and, instead, trying to resolve the structure vs. agency debate, we believe that Cardinale misunderstands the very essence of microfoundational research. Indeed, it is our contention that the most promising platform upon which to advance our understanding of the microfoundations of institutions is an explicit focus on how social action operates across multiple levels of analysis.

\section{References}

Battilana, J., \& D'Aunno, T. 2009. Institutional work and the paradox of embedded agency. Institutional Work: Actors and Agency in Institutional Studies of Organizations, $31-58$

Cardinale, I. 2018. Beyond Constraining and Enabling: Toward New Microfoundations for Institutional Theory. Academy of Management Review, 43(1): 132-155.

Coleman, J. S. 1986. Social theory, social research, and a theory of action. American Journal of Sociology, 1309-1335.

Cornelissen, J. P., Durand, R., Fiss, P. C., Lammers, J. C., \& Vaara, E. 2015. Putting Communication Front and Center in Institutional Theory and Analysis. Academy of Management Review, 40(1): 10-27.

Emirbayer, M., \& Mische, A. 1998. What is agency? American Journal of Sociology, 103(4): $962-1023$

Felin, T., Foss, N. J., \& Ployhart, R. E. 2015. The microfoundations movement in strategy and organization theory. The Academy of Management Annals, 9(1): 575-632.

Friedland, R., \& Alford, R. R. 1991. Bringing society back in: Symbols, practices and institutional contradictions. The new institutionalism in organizational analysis (Walter W. Powell and PaulJ. DiMaggio (eds.)): 232-263. 
Garud, R., Hardy, C., \& Maguire, S. 2007. Institutional entrepreneurship as embedded agency: An introduction to the special issue. Organization Studies, 28(7): 957.

Glaser, V. L., Fast, N. J., Harmon, D. J., \& Green Jr, S. E. 2016. Institutional frame switching: How institutional logics shape individual action. How Institutions Matter! 35-69. Emerald Group Publishing Limited.

Jepperson, R., \& Meyer, J. W. 2011. Multiple levels of analysis and the limitations of methodological individualisms. Sociological Theory, 29(1): 54-73.

King, B. G., Felin, T., \& Whetten, D. A. 2010. Perspective-Finding the organization in organizational theory: A meta-theory of the organization as a social actor. Organization Science, 21(1): 290-305.

Laureiro-Martínez, D., Brusoni, S., Canessa, N., \& Zollo, M. 2015. Understanding the exploration-exploitation dilemma: An fMRI study of attention control and decisionmaking performance. Strategic Management Journal, 36(3): 319-338.

McPherson, C. M., \& Sauder, M. 2013. Logics in Action Managing Institutional Complexity in a Drug Court. Administrative Science Quarterly, 58(2): 165-196.

Powell, W. W., \& Rerup, C. 2017. Opening the Black Box: The Microfoundations of Institutions. In R. Greenwood, C. Oliver, T. B. Lawrence, \& R. E. Meyer (Eds.). The SAGE Handbook of Organizational Institutionalism (2nd edition). Thousand Oaks: Sage.

Smets, M., Aristidou, A., \& Whittington, R. 2017. Towards a practice-driven institutionalism. In R. Greenwood, C. Oliver, T. B. Lawrence, \& R. E. Meyer (Eds.). The SAGE Handbook of Organizational Institutionalism (2nd edition). Thousand Oaks: Sage.

Thornton, P. H., Ocasio, W., \& Lounsbury, M. 2012. The institutional logics perspective: $A$ new approach to culture, structure, and process. Oxford: Oxford University Press. 
Udehn, L. 2002. The changing face of methodological individualism. Annual Review of Sociology, 28(1): 479-507.

Zucker, L. G. 1977. The role of institutionalization in cultural persistence. American Sociological Review, 42(5): 726-743. 